\title{
BUILDING EROSION CONTROL MEASURES IN LAND CONSOLIDATION PROJECTS
}

\section{ABSTRACT}

Anti-erosion protection is understood as a set of measures serving as process management to prevent soil loss and degradation of its productive and environmental potential. Anti-erosion protection is generally based on the influence of the subject of the erosion (soil) and erosion conditions, so in order to decrease the intensity of the erosion, it consists of a diverse set of measures, which are classified according to how they affect erosion. Soil erosion measures on agricultural land are divided as follows:

- Organizational measures: delimitation of land resources, cultural erosion and crop distribution, the size, shape and arrangement of land, the communication network, organization of grazing.

- Agrotechnical measures: Contour agrotechnics,

- Soil-protecting agrotechnics.

- Biological measures: crop belt, belt stabilizers, erosion crop rotations, conservation gins, protective afforestation.

- Technical measures: erosion channels, ditches, terraces.

\section{INTRODUCTION}

Erosion is the physical process of the demolition and removal of the earth's surface by the action of external (exogenous) factors [2].

Erosion is caused by the mechanical action of the surrounding matter, flowing or undulant water, ice, snow or wind, which result in the movement of loose sediments [2]. Then we judge the differentiation of kinds of erosion by dominant landscape-creating factors by which erosion is caused:

- water erosion,

- glacial erosion

- wind erosion
Erosion is a natural process, but in many places it is significantly accelerated by human activity, causing irreversible damage to ecosystems and loss of their functionality.

\section{EROSION THREAT TO SLOVAKIA}

In Slovakia there are about 1,359,000 ha of agricultural land potentially threatened by water erosion. Water erosion affects only about $6.5 \%$ of the agricultural land of SR - mostly in areas with light soils (Tab. 1, Fig. 1 ) [7].

The presence of glacial erosion in the SR is rare, so it will not be addressed in any detail. 


\section{IIOVALS JOUSSLAL \\ 0)

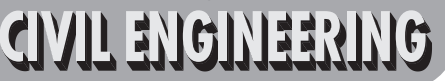

2011/2 PAGES $32-36$

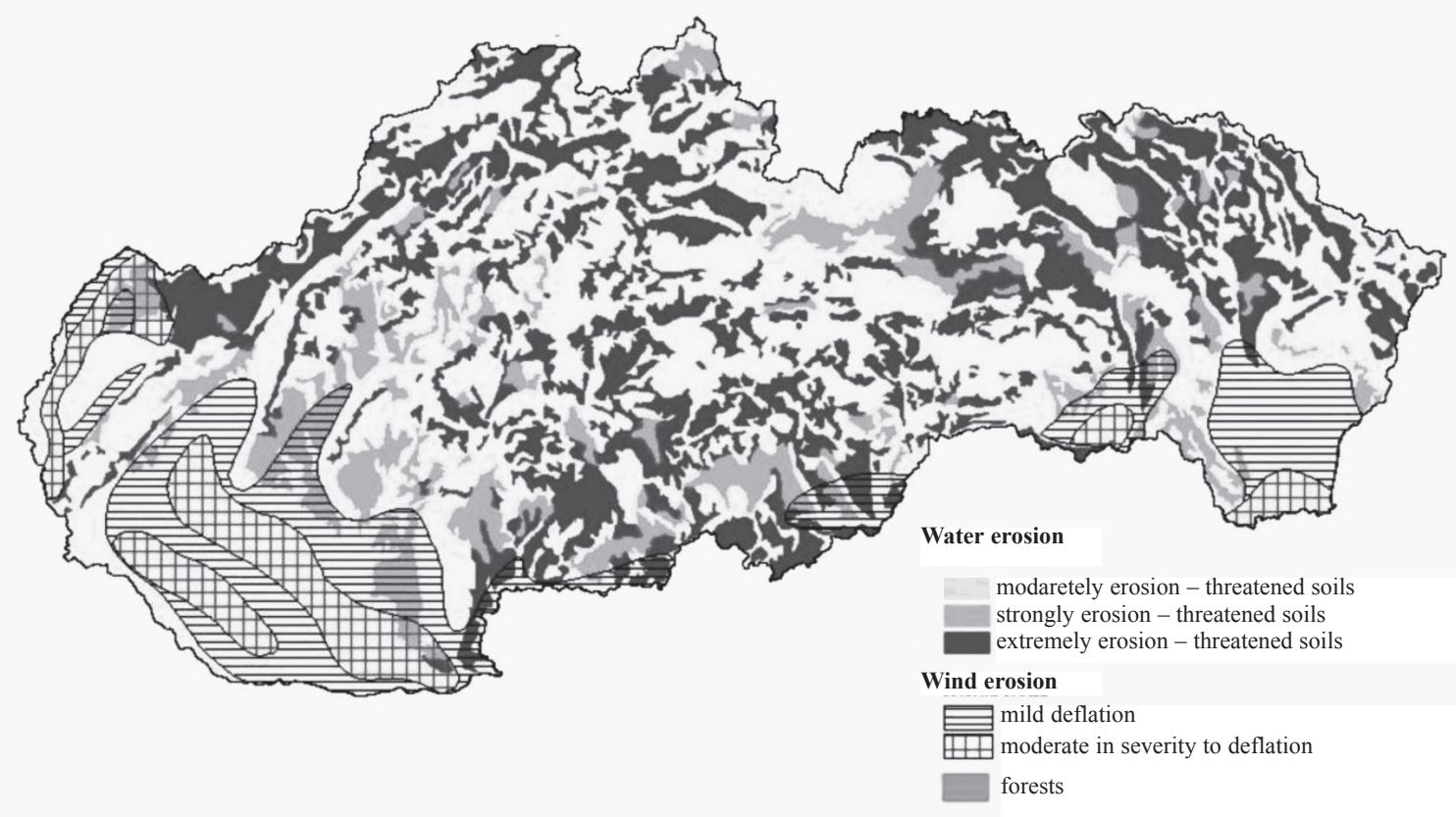

Fig. 1 Vulnerability of SR's agricultural land by water and wind erosion.

Tab. 1 Potential water erosion of the agricultural soils of the SR (000.ha).

\begin{tabular}{|l|c|c|c|}
\hline $\begin{array}{l}\text { moderately erosion } \\
\text {-threatened soils }\end{array}$ & 475 & 362 & 113 \\
\hline $\begin{array}{l}\text { strongly erosion - } \\
\text { threatened soils }\end{array}$ & 435 & 226 & 208 \\
\hline $\begin{array}{l}\text { extremely erosion - } \\
\text { threatened soils }\end{array}$ & 449 & 62 & 387 \\
\hline
\end{tabular}

PP - agricultural land, OP - plowable land, TTP - permanent grassy land

\subsection{Water erosion}

The current state of water erosion

Water erosion is a complex phenomenon that can be described as the loss of solid matter to a certain area for a period of time. The formation of erosion involves several factors:

- rain and surface runoff generated,

- geological and soil conditions,

- morphology of the territory,

- vegetation land cover,

- method of land use, etc.
A demonstration of water erosion is in Fig. 2.

To calculate the amount of water erosion, we mostly use the so-called universal soil loss equation, which determines the soil loss in $\mathrm{t} / \mathrm{ha} /$ year [7]:

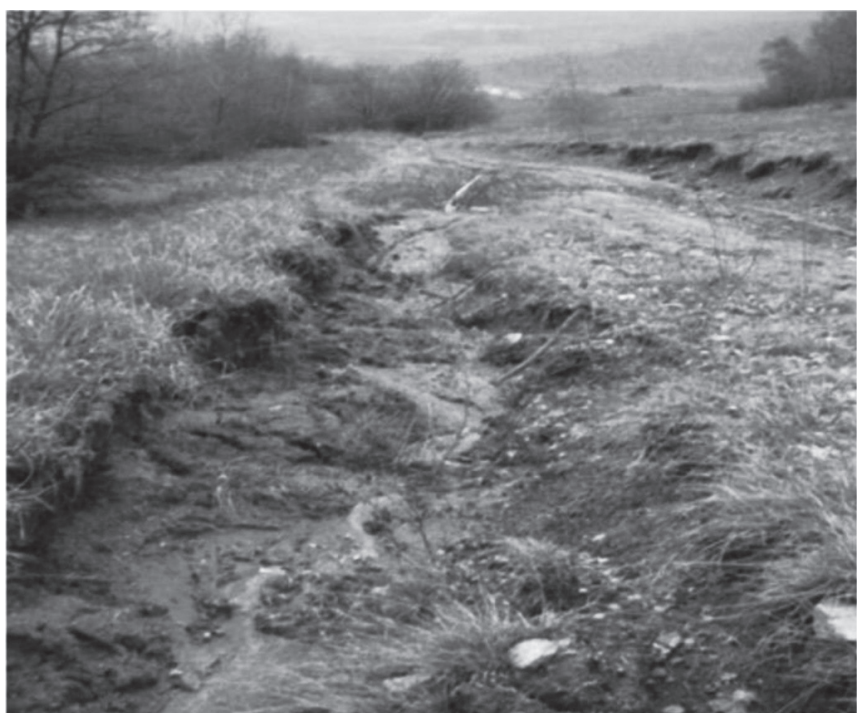

Fig. 2 Demonstration of water erosion. 


\section{$\mathbf{G}=\operatorname{RKLSCP}\left(\mathrm{t} . h a^{-1} \cdot \mathrm{r}^{-1}\right)$}

where:

$\mathrm{G}-$ soil loss $\left(\mathrm{t} \cdot \mathrm{ha}^{-1} \cdot \mathrm{r}^{-1}\right)$,

$\mathrm{R}$ - rainfall factor in erosion efficiency,

$\mathrm{K}$ - factor of tendency to soil erosion,

$\mathrm{L}$ - slope length factor,

$\mathrm{S}$ - slope gradient factor,

$\mathrm{C}$ - factor of protective impact of vegetation,

$\mathrm{P}$-factor of effect of anti-erosion measures.

In surface water erosion, the most important thing is to set the permissible length of the slope, which corresponds to the proposed width of the land or the whole amount of soil and in the direction of the gradient. It follows that human activity can affect erosion by setting the slope length of each particular acre and directing anti-erosion processes (contour cutting and planting strips in the contour).

\subsection{Wind erosion}

\section{The current state of wind erosion}

Wind erosion is caused by the mechanical strength of wind and is reflected in the eroding of a surface and the carrying away of fine to medium-grained soil particles. This erosion is reflected most notably in the spring when the soil structures are agitated. We can better see the strength of prevailing winds in table 2. The territory of the region of Humenné can serve us as an example.

To determine the extent of the potential vulnerability of an area to wind erosion, we often use the following formula:

$$
\mathrm{MEO}=(\mathrm{V} / \mathrm{S}) 100
$$

\section{where:}

$\mathrm{MEO}$ - rate of erosion vulnerability

$\mathrm{V}$ - maximum average speed of ground wind from the months of January to March over the past 10 years $(\mathrm{m} / \mathrm{s})$

$\mathrm{S}$ - the degree of dryness, which is determined from the absolute soil water capacity in $\% \mathrm{H}$.

$\mathrm{S}=\mathrm{H}-12$

\section{EROSION MEASURES IN LAND CONSOLIDATION}

Erosion measures are used in the protection of agricultural land. In particular, they are erosion limits, moats, infiltration strips, catch ditches, terraces, windbreaks, grassing, afforestation and so on.

The proposed common arrangements and measures (CFM) and public facilities and measures (PFM) in the land consolidation projects (LCP) are complementary and overlap. Elements of the territorial system of ecological stability (TSES) and a transportation network may also serve as controls of erosion and landscapes. Inherent in the cultural landscape are lakes, which help address the optimization of water conditions with their protective erosion control, and cleaning, hygiene and aesthetic features that contribute to the protection and development of the environment. At the same time over the long term they help water retention not only in the region, but also in the surrounding area, and prevent run-off to larger rivers and outside the territory of Slovakia.

\subsection{Technical solution of water erosion}

Technical anti-erosion measures against water erosion are the most effective. They are proposed for adjusting the slope of a terrain removal from a territory and safe (controlled) drainage water from surface run-off, soil material washed downstream and below. In land consolidation projects, it is possible to eliminate the effects of water erosion in general with the following proposal:

- Roadside ditches, dirt road network - Catchment drains, which catch and transfer surface rainwater from a road, with a longitudinal and transverse slope to the edge. Drains are usually designed in a trapezium shape along paved roads and a triangular shape along gravel roads which will be grassed. The proposed modifications, which are designed to prevent rainwater drip at the time of rainfall and melting snow in the spring, are open drainage channels reinforced with concrete tiles.

- Seductive trenches - Draining rainwater from existing slopes such as cemeteries, lawns, parks, etc., can be handled by a ditch, which usually flows along main or national roads. A sewer may generally be designed in a trapezoidal shape.

- Reinforcement of ditches is carried out by using concrete blocks such as TBM 8/30 - 50x30 cm, with a thickness of $10 \mathrm{~cm}$,

Tab. 2 Average frequency of wind directions - Humenné area[7].

\begin{tabular}{|c|c|c|c|c|c|c|c|c|c|}
\hline Month & $\mathrm{N}$ & $\mathrm{NE}$ & $\mathrm{E}$ & $\mathrm{SE}$ & $\mathrm{S}$ & $\mathrm{SW}$ & $\mathrm{W}$ & NW & No wind \\
\hline Humenné & 11.3 & 3.5 & 2.4 & 4.3 & 18.2 & 4.1 & 4.5 & 4.2 & 47.5 \\
\hline
\end{tabular}


which can be stored in a concrete bed on a sand-gravel base with a thickness of $10 \mathrm{~cm}$, etc.

- Crossing roads with proposed ditches to move the flow of rain water are generally proposed under roads, such as culverts of a diameter of 40-60 $\mathrm{cm}$ made of reinforced concrete pipes with fronts on both sides of the road.

\subsection{Technical solution for wind erosion}

Anti-erosion measures against wind erosion are based on the principles of the shape and configuration of the terrain. The effect of the erosion control of a properly structured vegetation cover of soil is reflected in particular:

- reducing wind speed,

- better management of snowfall,

- improving the microclimate of stands.

Windbreaks are chiefly proposed against wind erosion; they are semipermeable shrubs and are oriented upwind of trees. The width of windbreaks varies from 15 to 20 meters; sometimes a width of 8-12 meters is sufficient. Windbreaks are often designed from 1-2 rows of tall trees followed by one or two shrub belts. They are designed from the original tree species.

As a specific example in the design of anti-erosion measures in the Myslina land consolidation project in Slovakia, tree species of ash, beech, oak, maple, hornbeam and elm with other trees such as white and black poplars, plum, cherry and lime were primarily suggested (Fig. 3). The composition of the plant species is designed specifically for each cadastral area and is based on, for example, the original composition of the plants located in the area.

The influence of the most effective windbreaks on wind erosion cannot be mathematically documented. Windbreaks are designed so that the effect of an average wind speed is reduced by at least one third to one half, resulting in the reduction of the total erosion risk.

\section{REALIZATION OF ANTI-EROSION MEASURES AND THEIR IMPACT ON THE ENVIRONMENT}

Soil erosion control is a complex of organizational, agrotechnical, biological and technical measures, whose main objective is:

- prevent harmful erosion of vulnerable soils,

- reduce the intensity of erosion, not to exceed the limits of soil loss

- sustain the existing soil fertility at risk,

- prevent degradation of the land at risk or at least reduce the degradation,

- ensure the protection of resources lying below the surface and groundwater from the negative effects of eroded material,

- respect the environment.

The modification of an agricultural landscape is designed with minimal environmental or aesthetic impact on the surrounding environment. After planting trees and grassed open areas, there should be no deterioration in the environment in the locality in which such a restriction is made.

During the tree planting it is necessary to ensure the principles of civil coexistence and not to contaminate agricultural area with excessive noise and dust. Waste must be sent to the corresponding landfill or otherwise disposed of in an environmentally sound manner. Erosion control seeding has the same rules.

The effectiveness of protecting soil from water erosion is based on information about the spatial distribution of soils affected by erosion and its intensity in the specific conditions of the relevant sites. These institutions are being constructed with a minimal impact on agricultural land and must be compatible with the surrounding landscape and environment.

The goal of impact assessment of building anti-erosion measures is to provide area-wide indicators of the organic structure of the country on the basis of existing indicators in the country. The

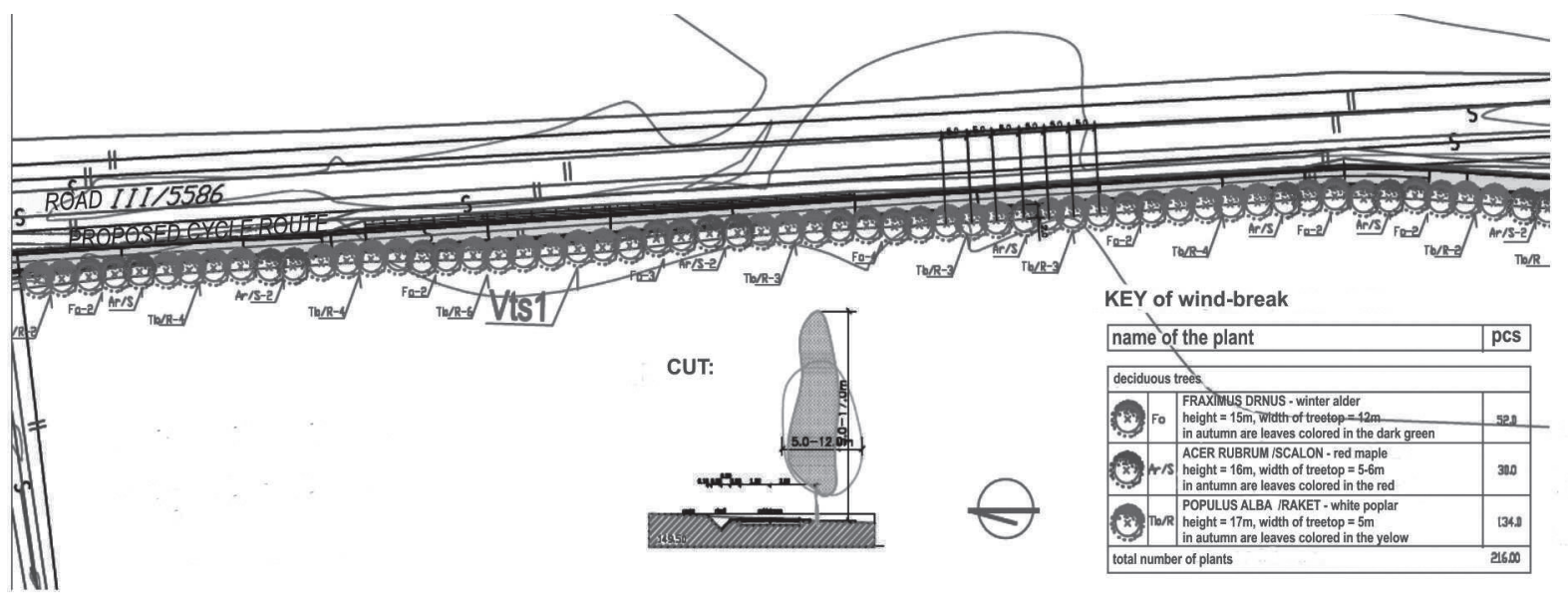

Fig. 3 The draft windbreaks around the communication activities of the Myslina land consolidation project. 
current landscape structure is the result of the long-term influence of anthropic pressure, which affects the degree of stability and quality of the landscape system. In assessing the ecological stability of the researched territory, we used a formula which balances the importance of the elements of a landscape structure.

The ecological stability coefficient (CES) is a function of the surface representation of the landscape elements and their degree of ecological stability ( $\mathrm{Si}$ ); it expresses the nature and ecological quality of a landscape's structure.

For the area of interest, we applied the relationship:

$$
C E S=\sum_{l}^{n} \frac{p i S i}{p}
$$

CES - coefficient of the ecological stability of the cadastral area pi - size of the individual elements of a landscape structure

$\mathrm{Si}$ - the degree of ecological stability of the investigated area

$\mathrm{p}$ - total area of cadastral area

$\mathrm{n}$ - number of elements in the cadastral area

1 - the impact of the landscaping element (m).

In determining the degree of ecological stability on the various landscape elements, we used a 6-level scale for rating the significance of a landscape in terms of the segment's environmental stability [8]:

\section{Distribution of levels of ecological stability:}

0- without relevance, there are, for example, areas and communications with asphalt or concrete surfaces

1 - very little importance have, for example, heavily exploited, large blocks of flat arable land

2 - little relevance to the objectives of the local territorial system of ecological stability and is attributed to intensive gardens, vineyards, intensified meadows

3 - grassed, extensively used gardens are of medium importance
4 - of great importance- forests and grasslands with a prevalence of naturally growing species and natural waters are included among these communities

5 - exceptionally important are natural forests, natural grass-herbal communities, wetlands, bogs, water stream areas with natural bottoms and shores, and characteristic coastal communities

In our case the calculated value of the CES of the current landscape structure is 2.65 , which means that our area has a medium degree of organic stability with a need for the conditional execution of new ecostabilization elements by selecting appropriate management measures. After realization of the ecostabilizing measures involved, the construction of anti-erosion measures should increase the value of CES to 3.11, which is still in the range for a country with a medium degree of organic stability but with a visible increase in the ecological stability of the territory.

Without the establishment and realization of anti-erosion measures, it is not possible to talk about meaningful land adjustments which have to represent an effective tool for improving the structure of the countryside of the 21 st century.

\section{CONCLUSION}

The above example of soil erosion shows that erosion is a major factor threatening agricultural land, the existence of which must be taken into account in the realization of land consolidation. Land consolidation is desirable in a form that takes account of the need for anti-erosion protection and thus contributes to maintaining the productive and environmental potential of the land.

Such an understanding of land consolidation supported by law creates conditions for taking the needs of erosion protection into account and integrally incorporating them in land consolidation projects.

\section{REFERENCES}

[1] Act. No 330/1991, about land consolidation, arrangement of land ownership, land offices, land funds and land communities.

[2] Act. No 543/2002: about the protection of nature and land.

[3] Ščepita, O., Bahna, J., Korkobec, R.: Myslina land consolidation project, 2006.

[4] Alena, F.: A methodological guide for designing erosion control measures for an agricultural land fund, within a comprehensive fertilizing landscape, Bratislava 1973.
[5] Alena, F.: Erosion protection on arable land: methodological guide, Bratislava 1991.

[6] Antal, J.: Erosion on agricultural lands: research report, Nitra 1995.

[7] http://www.sazp.sk.

[8] Löw, J., et al: Designer handbook of local territorial system of ecological stability, extended edition Brno, p. 124, 1995. 